Forum 2016 $31: 439$

DOI 10.1007/s12312-016-0135-4

29. September 2016

○) Springer-Verlag Berlin Heidelberg 2016

HAMBURGER ::: KREBSGESELLSCHAFt E.V.

Taubheitsgefühl, Kribbeln oder Schmerzen in Händen und Füßen - für viele Krebspatienten sind die Begleiterscheinung der Therapie sehr belastend. Das zeigte sich auch in dem großen Interesse an dem Patientenforum mit dem Titel „Polyneuropathie durch Krebstherapie - Was kann ich tun?" der Hamburger Krebsgesellschaft am 14. Juli: Zum ersten Mal hat die HKG ein Patientenforum zu diesem Thema angeboten, die Veranstaltung war restlos ausgebucht.

Dr. med. Monika Steimann, Chefärztin und Klinikleitung der Strandklinik Boltenhagen, klärte ausführlich und gut verständlich über die Entstehung der Chemotherapie-induzierten Polyneuropathie und ihre Behandlungsmöglichkeiten auf. Im
Hamburger Krebsgesellschaft e.V., Hamburg

\section{Patientenforum Polyneuropathie der Hamburger Krebsgesellschaft}

Anschluss wurde es praktisch: Physiotherapeutin Sybille Reinauer aus dem Universitätsklinikum Hamburg-Eppendorf zeigte viele hilfreiche Übungen und animierte das Publikum zum Mitmachen. Und zum Abschluss durften sich alle Teilnehmer auf dem extra angelegten Barfußparkour im Garten selbst erproben (• Abb. 1).

\section{Korrespondenzadresse}

\section{Kathrin Armbruster}

Presse- und Öffentlichkeitsarbeit

Hamburger Krebsgesellschaft e.V.

Butenfeld 18|22529 Hamburg

Tel.: $04041347568-0$

E-Mail k.armbruster@krebshamburg.de

www.krebshamburg.de

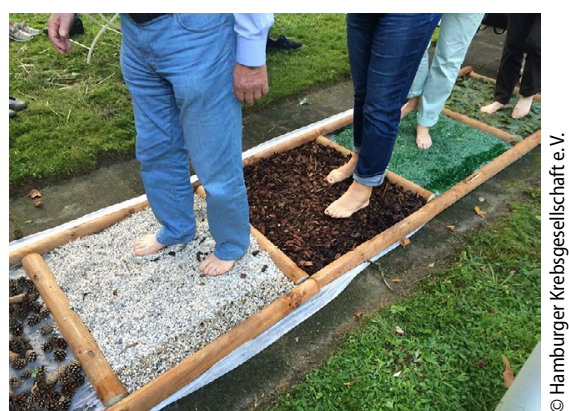

Abb. 1 ॥ Ein extra angelegten Barfußparkour animierte die Teilnehmer zum Mitmachen

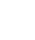

